\title{
Radiotherapy on knee-related pigmented villonodular synovitis
}

\begin{abstract}
Pigmented villonodular synovitis (PVNS) is a rare, proliferative disease of synovium. Despite the benign histological character, recurrent surgery need may be necessary because of frequent recurrence. ${ }^{1}$ The lesion generally holds the knee and it is separated into two as local and diffuse. ${ }^{2}$ Excision results in local form are more successful than the diffuse form. Diffuse form has a higher recurrence rate. ${ }^{3}$ Treatment includes open excision, arthroscopic synovectomy, open and arthroscopy assisted synovectomy and radiation therapy after synovectomy. ${ }^{4-7}$
\end{abstract}

Volume 5 Issue 6 - 2018

\author{
Sefa Giray Batibay,' Sevilay Batibay² \\ 'Orthopedics and Trauma Department, Medical Science \\ University, Turkey \\ ${ }^{2}$ Physical Therapy and Rehabilitation Department, Haydarpasa \\ Research and Education Hospital,Turkey
}

\begin{abstract}
Correspondence: Sefa Giray Batibay, Orthopedics and Trauma Department, Medical Science University, Derince Research and Education Hospital, , Kocaeli Turkey, Tel 090 50529598I7, Email sefabatebay@hotmail.com
\end{abstract}

Received: May 23, 2018 | Published: November 26, 2018

\section{Methods}

After making scans on Pubmed, we found studies written in English, and that are made after 01.01.2000, to examine in our study. Case reports are left out of the study. Exclusion criteria were the ones cannot be found as a whole text, having extra articular diseases, the ones who are not planned to be implemented radiotherapy, and whose disease are not knee-related.

\section{Results and discussion}

In Carvalho et al.'s study, recurrence was observed in 1 patient at 8.6 years follow-up after external beam radiotherapy in 8 patients. Patient are implemented an average of 2000 cGy dose of 10 sessions of radiotherapy. ${ }^{8}$

In a series of 22 patients of Blanco, recurrence was observed in 3 patients $(13.6 \%)$. After arthroscopic synovectomy, in the form of external beam radiotherapy; a total dose of 2600 cGy radiotherapy was used. ${ }^{9}$

Berger implemented external beam radiotherapy in the range of 30 to $50 \mathrm{~Gy}$ after open synovectomy in 7 patients. With no recurrence on the patients, it is stated that 1 patient complains about joint stiffness. ${ }^{10}$ Nassar et al., ${ }^{11}$ did not report recurrence in the study involving 12 patients with an average follow-up of 27 months after postoperative radiotherapy. ${ }^{11}$ Ozturk et al. ${ }^{12}$ did not report recurrence in the study involving 7 patients with an average follow-up of 47.8 months postoperatively. ${ }^{12}$

Chan et al..$^{13}$ determined recurrence on 5 patients among 19 patients, on this study follow-up time is longer than the others, 98 months. ${ }^{13}$ On Wu's study, among 9 cases, only 1 recurrence is reported, stated that the patient is extraarticular attitude. ${ }^{14}$ On a retrospective study with 40 patients, patients are divided into 3 groups as only surgical resection, surgical and preoperative radiotherapy, and postoperative radiotherapy. On the result of study, it is emphasized that radiotherapy is more effective on the small lesions, but what is important is, radical surgery. Only 2 recurrences were determined out of a series of 49 patients, on the study of Griffin et al. Radiotherapy dose was measured as 39,8 grays mean.
With monitoring radiotherapy was implemented in different doses on the studies, there is no consensus. On their study with 23 patients, Park et al stated that the total radiation dose is not predictive on the control of the local control of the disease. There are lots of restrictive factors in our study. Restriction of the study amount is an example of bias factors that can occur.

\section{Conclusion}

Radical synovectomy could be technically hard on diffuse PVNS. We should think of adding radiotherapy when it is seen that excision will not be enough on preoperative planning.

\section{Acknowledgments}

None.

\section{Conflicts of interest}

The authors declare that there is no conflicts of interest.

\section{References}

1. Myers BW, Masi AT. Pigmented villonodular synovitis and tenosynovitis: a clinical epidemiologic study of 166 cases and literature review. Medicine. 1980;59(3):223-238.

2. Granowitz SP, D’Antonio J, Mankin HL. The pathogenesis and longterm end results of pigmented villonodular synovitis. Clin Orthop Relat Res. 1976;114:335-351.

3. Zvijac JE, Lau AC, Hechtman KS, et al. Arthroscopic treatment of pigmented villonodular synovitis of the knee. Arthroscopy. 1999;15(6):613-617.

4. Ogilvie-Harris DJ, McLean J, Zarnett ME. Pigmented villonodular synovitis of the knee. The results of total arthroscopic synovectomy, partial arthroscopic synovectomy and arthroscopic local excision. $J$ Bone Joint Surg Am. 1992;74(1):119-123.

5. Granowitz SP, D’Antonio J, Mankin HL. The pathogenesis and longterm end results of pigmented villonodular synovitis. Clin Orthop Relat Res. 1976;114:335-351.

6. Horoschak M, Tran PT, Bachireddy P, et al. External beam radiation therapy enhances local control in pigmented villonodular synovitis. Int $J$ Radiat Oncol Biol Phys. 2009;75(1):183-187. 
7. Griffin AM, Ferguson PC, Catton $\mathrm{CN}$, et al. Long-term outcome of the treatment of high-risk tenosynovial giant cell tumor/pigmented villonodular synovitis with radiotherapy and surgery. Cancer. 2012;118(19):4901-4909.

8. de Carvalho LH Jr, Soares LF, Goncalves MB, et al. Long-term success in the treatment of diffuse pigmented villonodular synovitis of the knee with subtotal synovectomy and radiotherapy. Arthroscopy. 2012;28(9):1271-1274.

9. Blanco CE, Leon HO, Guthrie TB. Combined partial arthroscopic synovectomy and radiation therapy for diffuse pigmented villonodular synovitis of the knee. Arthroscopy. 2001;17(5):527-531.

10. Berger B, Ganswindt U, Bamberg M, et al. External beam radiotherapy as postoperative treatment of diffuse pigmented villonodular synovitis. Int J Radiat Oncol Biol Phys. 2007;67(4):1130-1134.

11. Nassar WA, Bassiony AA, Elghazaly HA. Treatment of diffuse pigmented villonodular synovitis of the knee with combined surgical and radiosynovectomy. HSS J. 2009;5(1):19-23.
12. Ozturk H, Bulut O, Oztemur Z, et al. Pigmented villonodular synovitis managed by Yttrium 90 after debulking surgery. Saudi Med J. 2008;29(8):1197-1200.

13. Chen WM, Wu PK, Liu CL. Simultaneous Anterior and Posterior Synovectomies for Treating Diffuse Pigmented Villonodular Synovitis. Clin Orthop Relat Res. 2012;470(6):1755-1762.

14. Wu CC, Pritsch T, Bickels J, et al. Two incision synovectomy and radiation treatment for diffuse pigmented villonodular synovitis of the knee with extra-articular component. Knee. 2007;14(2):99-106.

15. Chin KR, Barr SJ, Winalski C, et al. Treatment of advanced primary and recurrent diffuse pigmented villonodular synovitis of the knee. $J$ Bone Joint Surg Am. 2002;84:2192-2202.

16. Park G, Kim YS, Kim JH, et al. Low-dose external beam radiotherapy as a postoperative treatment for patients with diffuse pigmented villonodular synovitis of the knee. Acta Orthop. 2012;83(3):256-260. 